\title{
Polyhouse Agricultural Marketing System Using Big Data Hadoop
}

\author{
Ayesha Bhandralia*, Resham Arya ${ }^{*}$, S. N. Panda**, Sachin Ahuja** \\ Computer Sciences, Chitkara University, Rajpura, India \\ CURIN, Chitkara University, Rajpura, India
}

\begin{tabular}{l}
\hline \hline Article Info \\
\hline Article history: \\
Received Mar 8, 2016 \\
Revised May 10, 2016 \\
Accepted May 21, 2016 \\
\hline
\end{tabular}

Keyword:

E-PAM

Market Channelization

MongoDB

Polyhouse

\begin{abstract}
Agriculture is to cultivate and produce crops and livestock products. Agriculture in its associated sectors is unquestionably the largest livelihood provider, in the broad areas of rural India. With the emergence of high tech agriculture farming known as Polyhouse farming came into existence. Polyhouse farming is an alternative new technique which reduces clinging on to natural procedures that are very basic needs of agriculture i.e. rainfall, temperature, humidity and geographical conditions and this result in the most advantageous use of water and land resources. Polyhouse advances to create suitable microclimates, which favour the crop production by simulation of artificial environment using latest computer assisted technology. Yet polyhouse product marketing is an uncovered area which is still neglected and there is a strong need to for an effective marketing intervention or channelization. The liberalized trade environment in general has added another dimension to the poverty of farmers and uncertainty about the future. The paper describes the long established approach of marketing concept of polyhouse agriculture. The relationship between development, marketing and accessibility in polyhouse agriculture is reviewed. We have detected various inadequate parameters, and recognized the need of an effective polyhouse marketing system which may have beneficial impact on farmers.
\end{abstract}

Copyright $@ 2016$ Institute of Advanced Engineering and Science. All rights reserved.

\section{Corresponding Author:}

Ayesha Bhandralia,

Department of Computer Science \& Engineering,

Chitkara University,

Rajpura, Punjab, INDIA - 140401.

Email: ayesha.20191@gmail.com

\section{INTRODUCTION}

Agriculture and human social development go side by side as the production of crops made it possible for primitive man to settle down in selected spots leading to formation of society. Discovery of agriculture phase was from 7500-6500 B.C. The history of agriculture dates back thousands of years, and its growth has been driven and defined by greatly different cultures, climates, and technologies. It is the backbone of Indian Economy. In India, Agriculture and allied sectors like forestry and fisheries accounted for $13.7 \%$ of the GDP(Gross Domestic Product) in 2013, about 50\% of the entire human resources. In India, more than $70 \%$ of the population is depending on agriculture in one form or the other. The current population is about 1000 million which is expected to stabilize at about 1500 million by the middle of present century. Population rise has created disturbing situation as the horizon of increasing area under production of the crops is limited. The financial involvement to India's GDP through agriculture is steadily dwindling with broad-based economic growth of the country. But still the agriculture is demographically the broadest economic zone and plays a significant role in the overall socio-economic of India.

Despite of economic development and industrialization, agriculture is the mainstay of the Indian economy. India is a country with distinct agriculture trends. The country holds vast expanse of plain as well as sloppy land, soil rich in minerals, wild climatic alterations suited for variety of crops, a long growing 
season and ample sunshine. The net total sown area in India today is about 143 million hectares. India enfolds the highest percentage of land under cultivation around the world. In spite of the fact that India has a large area, after independence, have been brought under irrigation, only 1/3rd of the cropped area is actually harvested. The productivity of agriculture is very low. Farming relies mainly upon monsoon rain. Most of the production constitutes food crops. About 1/3rd of the land holdings are small in size, less than one hectare. Farmers own their own small pieces of land and grow crops primarily for consumption. Even the storage for crops is inadequate. The use of pesticides and fertilizers has increased and large areas have been brought under high yielding variety of seeds. This has led to polyhouse farming in several parts of India. Polyhouse farming provides an effective solution to the problems that relate to almost every aspect of agriculture in India hence there is a strong need to promote polyhouse farming with immediate effect.

\subsection{Polyhouse}

Our diet constitutes cereals, pulses, fruits, and vegetables. The majority of Indian population do not incorporate enough quantities of fruits and vegetables in their regular diet and intake of food become imbalanced. The fruits and vegetables are missing in the diet of poor marginal Indian because of their overall shortage. Majority of farmers are not ready to shift their crop land to fruits and vegetable cultivation, hence under such condition poly houses can be the only answer for this.

A poly house is also acknowledged as a poly tunnel, hoop greenhouse. It is a tunnel made of polyethylene, generally semi-circular, square or cylindrical in shape. The inside of the polyhouse heats up because incoming solar radiation from the sun warms plants, soil, and other things inside the building fast which is retained in the structure by the roof and wall. Humidity, temperature and ventilation inside the structure can be controlled by equipment fixed in the poly tunnel. Poly house cultivation as well as other modes of controlled environment cultivation has been evolved to create favourable micro-climates, which indicates that the crop production could be possible all through the year or part of the year as required. Poly houses for controlled environment plant production are associated with the off-season production of ornamentals and foods of high value in cold climate areas where outdoor production is not possible. The primary environmental specification traditionally controlled is temperature, generally providing heat to overcome extreme cold conditions. Nevertheless, environmental control can also include cooling to mitigate excessive temperatures, light control, carbon dioxide levels, water, relative humidity, plant nutrients, and pest control and plant nutrients.

The poly house technologies are advanced in Israel, Holland, Spain, Italy, Kenya, South Africa, Japan and China. But unfortunately much neglected in India. India and Holland having more or less same land under flower cultivation but in world's flower export, Holland's contribution is $70 \%$ and India's contribution is just $1 \%$ or even less because of advanced technology of poly houses in Holland. Maharashtra is promoting poly house technology for cultivation of Gerbera, Carnation, Roses, Anthurium and some exotic vegetables. About 1500 Poly houses of 5 Gunthas(5000Sq Feet) and 10 Gunthas(10000 Sq Feet) capacity are under production but still farmers are not getting enough out put due to lack of guidance from expert horticulturists. Banks are also reluctant to give finance because of unaware of knowledge in this field.

\subsection{Polyhouse Farming and Marketing}

The innovative and lucrative techniques of farming inside polyhouses to grow vegetables has turned out to be ideal in harsh winters when little cultivation is possible in the hill state, particularly for farmers with small land holdings [1]. Polyhouse farming has helped in increasing yields per hectare as well as total production of different crops. Possibly, polyhouse farming can help the farmer engender income around the year growing multiple crops due to good market value of high quality crops. Government of India gives $50 \%$ subsidy for low cost polyhouses, $20 \%$ for medium cost polyhouses and $10 \%$ for high cost polyhouses as an incentive [2]. It enables cultivation of crops that can give maximum yield on specific days (e.g. roses on Valentine's Day, carnations, gerbera, orchids on Festivals or Weddings) and exotic crops that can't be normally grown in Indian conditions (e.g. colored capsicum, broccoli and mushrooms). Polyhouse farming is today manifest to be game changer and therefore should supply security for customers with strong back end linkage.

A manifold increase in the resource-use efficiency in crop production can be obtained through protected cultivation when compared with the open field conditions. Therefore, the crop cultivation in polyhouses can work wonders for the marginal and small farmers provided the extension services for transfer of scientific crop production technology in polyhouses are further speeded up endeavourly [3]. To enhance income and to ensure nutritional security of the small and marginal farmers, off-season nursery as well as vegetables cultivation under low cost poly houses is found to be economical and profitable enterprise [4].

Over centuries, farmers in this country devised practices to keep our farms sustainable. Practices like mixed cropping, crop rotation, using organic manure and pest management kept our agriculture 
sustainable. But things changed for the worse with the onslaught of a chemical intensive model of agriculture, imposed through the so called Green Revolution in 1965. In India around 70\% of the population earns its livelihood from agriculture. It still provides livelihood to the people in our country. It fulfils the basic need of human beings and animals. It is an important source of raw material for many agro based industries. India's geographical condition is unique for agriculture because it provides many favourable conditions. There are plain areas, fertile soil, long growing season and wide variation in climatic condition etc. Apart from unique geographical conditions, India has been consistently making innovative efforts by using science and technology to increase production. India has shown a steady average nationwide annual increase in the kilograms produced per hectare for various agricultural items, over the last 60 years. These gains have come mainly from India's Polyhouse Agriculture, improving road and power generation infrastructure, knowledge of gains and reforms.

Indian polyhouse agriculture is identified by need of strong linkages between production and marketing strategies and inadequate marketing infrastructure. The imbalance induced market surplus in case of many crops. The challenges posed by the surplus crop production and most importantly by the liberalized trade environment globally, can be met only by having a sound agricultural marketing system in our country. It has been realized that polyhouse agriculture development has to be market driven and responsive to the changed world trade environment. The challenges posed by the surplus crop production and most importantly by the liberalized trade environment globally, can be met only by having a sound agricultural marketing system in our country [5].

\subsection{Need of Polyhouse Agricultural Marketing System \\ 1.3.1. Introduction}

The importance of competitive and effective marketing system has been stressed as a complement to infrastructure in promoting development. Where populations are dispersed markets are also likely to be dispersed with long average distances to market and people less likely to make the trip. This is an important consideration for the demand for Polyhouse agricultural marketing system where, if distances become too large. In addition, one of the most effective ways that farmers have of getting the best price for their produce is for them to sell it themselves directly to final consumers through a portal at urban markets, and thus bypass the normal marketing system.

The development of marketing strategies, information dissemination and connectivity between the customer and farmer across all regions uniformly can improve productivity. Therefore, this marketing system can play a useful role in agricultural marketing.

\subsubsection{Need of Polyhouse Marketing System}

Existing technology is not efficient to fulfil the commodities of a customer by farmer. The farmer is unaware of the demand and therefore is not able to supply accordingly. Despite this, at times farmers have to sell the crop for lower price to compete with the ordinary farm products which are available cheaper. According to our literature survey, we need to make sure that we eliminate the problem using a system to facilitate farmers to take right decision for the crop to cultivate so that it will not be flooded in the market and customer to get its commodities as per the requirement. Instead of providing subsidy to the farmers, government should provide a platform. Therefore, we need a system which may act as a strong communication interface between farmers and customers. An effective e-commerce framework using Big Data analytics can be developed for strengthening the relationship between farmer and customer and to create a sustainable supply demand chain in polyhouse farming. Initially the system can be deployed at small scale area and further to a broad area.

\section{PROPOSED ELECTRONIC POLYHOUSE MARKETING SYSTEM (E-PAM)}

\subsection{Overview}

E-pam is Electronic polyhouse agricultural marketing system to be developed using latest programming language best suited to work in a distributed environment and an robust database management system based on HADOOP architecture for handling future needs of large volume of data to be stored and managed with the help of big data analytics.

\subsection{Objectives}

1. To develop responsive, highly dynamic online platform or system, this may act as a strong communication interface between farmers and customers.

2. An effective framework management to create a sustainable supply demand chain in Polyhouse farming. 
3. To create an efficient database using Apache Hadoop for availability of data understanding the importance of reliable and timely information.

4. To avail useful, adequate, relevant information about major production of crops to customers.

\subsection{Process}

The front end web interface of the E-PAM system will be developed using web development language PHP and Bootstrap. The PHP Hypertext Preprocessor (PHP) is a server side scripting language. This language is designed for web development but also used as a general-purpose programming language. It is generally used for developing simple, dynamic web based software applications. It is used to manage dynamic content, session tracking, databases and build e-commerce sites. It is integrated with ample of wellknown databases, like MySQL, Oracle, Informix, PostgreSQL, Microsoft SQL Server, and Sybase. Whereas Bootstrap is a front end framework which contains collection of tools for HTML and CSS based design templates. Bootstrap emphasizes responsive design by default.

The back end relational database system will be designed and developed using Apache Hadoop File System (HDFS). Hadoop is a Top level Apache project open source software framework that's written in javaprogramming language [6]. Apache Hadoop platform develops open-source software for consistent, scalable, distributed evaluation. Hadoop software library is a structure that allows for the distributed processing of huge data sets across clusters of computers using effortless programming models. It is designed to promote from solitary servers to thousands of machines, each offering local calculations and storage. Instead of relying on hardware to deliver high -accessibility, the library itself is designed to perceive and handle failures at the application layer, so delivering a highly obtainable service on top of a cluster of computers[7]. Forrester regards Hadoop as the most significant part of the next-generation Enterprise Data Warehousing (EDW) in the cloud [8].

\subsection{Implementation}

This E-PAM system which strengthens the relationship between customer and farmer is designed with the help of two softwares. The GUI (Graphical user interface) is developed by using web development language PHP and in Bootstrap. This framework is broadly divided into three domains: Administrator domain, Farmers domain and Marketing(user) domain.

\subsubsection{Administrator Domain}

The admin is basically the owner of this site which will do all the management work. He can perform addition and deletion of any data. Admin can view all the farmers details which are already registered with this website.

- He can also view the details and list of the users (customers) which are linked with this site.

- Admin can view all the registered polyhouses. He can also upload the videos related to agricultural system.

- He also has the list of all the products which can be grown in the polyhouses.

- He will manage the warehouse and database of farmer and customer and moreover deals with transportation of the crop.

\subsubsection{Farmers Domain}

This domain stores the information about the farmer, his polyhouses and the details of all products produced in polyhouses. The farmers have their own different login system and following features:

- Farmers can easily establish proper market channel and advertise their products which helps them economically a lot.

- They have the facility to add new polyhouse online which will store the information about the product, date of sow and harvesting, total quantity of the product in polyhouse.

- Farmer can also view the history of orders.

\subsubsection{Marketing Domain}

In this domain the information of customers is stored. The customers are those who purchase products from the polyhouses online. This system will help the customers to locate nearby polyhouses and their various organic commodities from where they can easily place their order and also get the idea of delivery date which will be done by any courier system. With this users can update their profile including personal details and the polyhouse details also. 


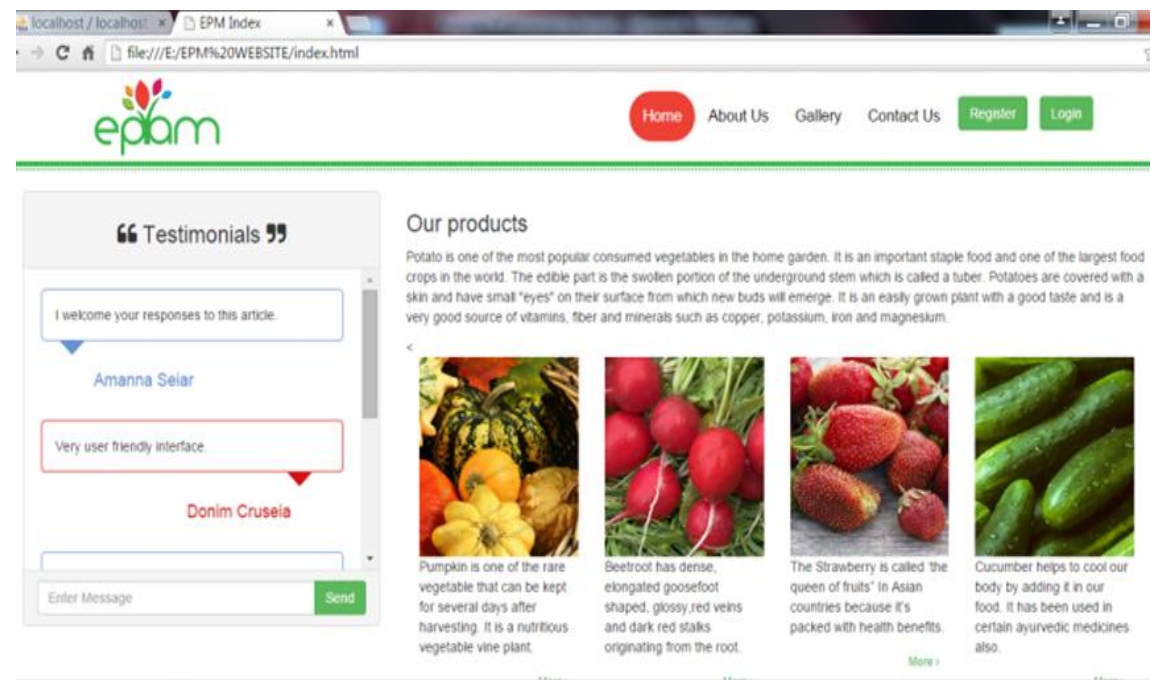

Figure 1. Design Layout of E-PAM (Front End)

New cloud computing technologies such as Hadoop, MapReduce and BigTable are driving analytic transformation in the way organizations store, access and process massive amounts of disparate data via massively parallel and distributed IT systems. Cloud produces the new analytic capabilities of big data. And it provides massively scalable analytics and third reason is all facilities listed above are combined with the security and financial advantages of switching to a cloud computing environment [9].

The backend database is developed using Hadoop Core where we are using NOSQL MongoDB technology. The Hadoop core consists of a set of components and interfaces which provides access to the distributed filesystems and general I/O [10]. MongoDB is cross platform open-source document oriented database. It is classified as NOSQL making the integration of data in certain types of applications easier and faster.

Some of the main features include Document-oriented, MongoDB supports search by field, range queries, regular expression searches and any field in a MongoDB document can be indexed. MongoDB provides high availability with replica sets while the data is eventually consistent by default. MongoDB can run over multiple servers, balancing the load and/or duplicating data to keep the system up and running in case of hardware failure. MapReduce can be used for batch processing of data and aggregation operations. The aggregation framework enables users to obtain the kind of results for which the SQLGROUP BY clause is used. JavaScript can be used in queries, aggregation functions (such as MapReduce), and sent directly to the database to be executed.

We have used Parse.com cloud platform as it has MondoDB as its base database. Parse in a Backend provider which allows application developers to forget about server maintenance and complex infrastructure, and instantly add push notifications, data storage and social integration to their applications.

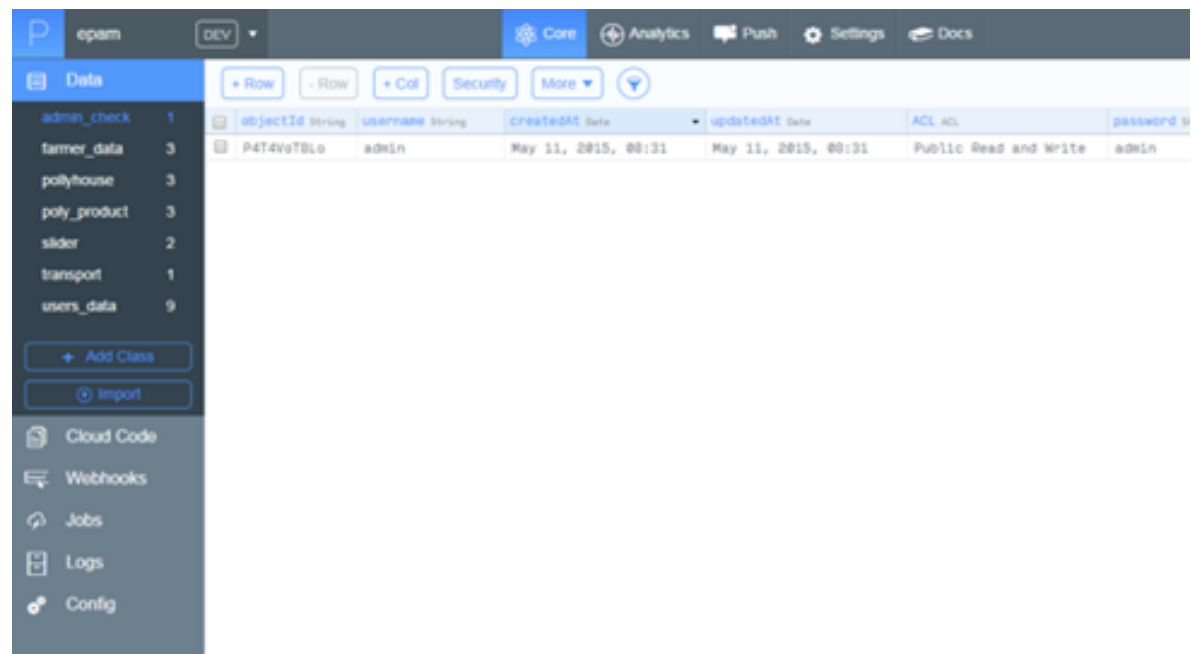

Figure 2. MongoDB Database 


\section{ANTICIPATED IMPACT}

The Poly house agriculture paved the way for food security in India. No major technological development has emerged since then. Marketing of the Poly house agriculture produce is essential to sell as they are organically cultivated. As farmers sell their produce to commodity agents and those agents sell them further in market at higher rate which results in great loss to farmers. So an E-PAM system can provide farmers a platform from where they can advertise their poly house produce, build a contemporary market channel and accord directly with the customers. An effective Relational Database structure can be designed using Big data tool HADOOP having HDFS File System for Poly house Framework which governs the whole information regarding both farming and marketing aspects. This information can benefit the farmers in establishing a good network with the market. It can also guide them in taking better decision that what type and at what time they should grow that commodities which helps in increasing their economic growth. It also stores the stock and order details of customers.

\section{CONCLUSION}

Our proposed system can provide effective marketing supply-demand need. Poly house farming needs better support system. Marketing of the products is essential to sell the organic products cultivated in the poly houses. As farmers sell their products to commodity agents and those agents sell them further in market at double rate which is actual great loss to farmers. So this proposed system will provide farmers a platform from where they can advertise their poly house products, establish a new market channel and deal directly with the customers. Thus, EPAM enable the farmers to respond better to markets by augmenting or changing their production. Additionally, they reduce losses. EPAM may operate more efficiently on short distances with small loads to deliver through a transport system. And still if the polyhouse is located more than a half a day's travel, a transport system is cost effective solution.

\section{REFERENCES}

[1] Ashwani Sharma, "Prosperity in a polyhouse", Indian Express. 2011.

[2] Neha Madme, Anirudha Joshi, "System for Polyhouse Farmersand Consultants", Conference held by USID Foundation in September, Hyderabad, India. 2009.

[3] Dr. Brij Bala, "Upliftment of Rural Economy Through Protected Cultivation”, International Global Research Analysis, 2013: 2: 42-43

[4] R.K.Yadav, P.Kalia, H.Choudhary, Zakir Husainand BrihamaDev, "Low-Cost Polyhouse Technologies for Higher Income and Nutritional Security", International Journal of Agriculture and Food Science Technology. 2014: 5: 191-196.

[5] G.H. Dhanekar, "Development of Internet based Agricultural Marketing Information System in Indian Agricultural Marketing", Agricultural Marketing. 2003.

[6] http://hadoop.apache.org/

[7] Yan, Zi Jian, Peng Sun, and Xiao Mei Liu. "An HBase-Based Platform for Massive Power Data Storage in Power System", Advanced Materials Research, 2014.

[8] The Forrester Wave ${ }^{\mathrm{TM}}$ : Enterprise Hadoop Solutions, Q1. 2012.

[9] Hamid Bagheri, Abdusalam Abdullah Shaltooki, "Big Data: Challenges, Opportunities and Cloud Based Solutions", International Journal of Electrical and Computer Engineering (IJECE), April 2015: 5(2): 340-343.

[10] Rabi Prasad Padhy, "Big Data Processing with Hadoop-MapReduce in Cloud Systems", International Journal of Cloud Computing and Services Science (IJ-CLOSER). February 2013: 2(1): 16-27.

\section{BIOGRAPHIES OF AUTHORS}

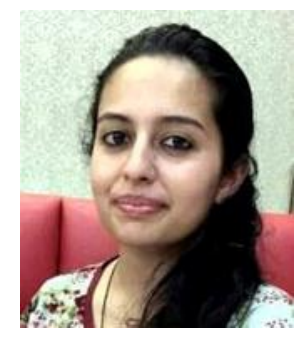

Ayesha Bhandralia, currently working as a research scholar in Chitkara University. She received her B.E. from Chitkara University. Her research interest area is in Web Development languages. She also worked on a project titled "Point of Sale". 


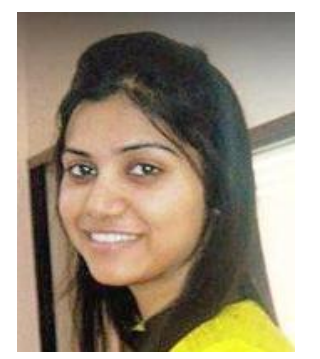

Resham Arya, currently working as a research scholar in Chitkara University. She received her B.tech from Chitkara University. Her research interest area is Databases and Big Data systems. She also worked on a Database Structure comparison tool for Chalkpad Technologies, Chandigarh.

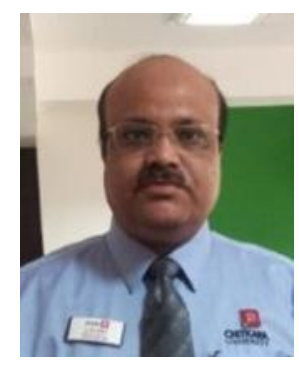

Dr.S.N.Panda is Prof. \& Director (Research) at Chitkara University, Punjab. His research expertism is in Network Security, Cyber Security, Inter Disciplinary Research using VPN, HADOOP.

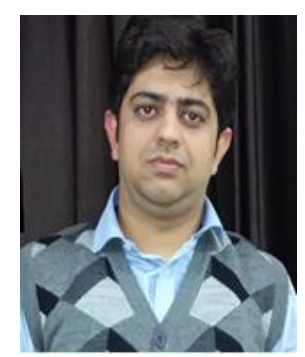

Dr. Sachin Ahuja obtained his PhD in Computer Science \& Engineering in the year 2013. Prior to that he did his Master of Technology from UPTU, Lucknow, and Uttar Pradesh, India in the year 2010. He has over 10 years of experience in teaching and research at UG and PG levels of Computer Science \& Engineering. His research interests include: Data Mining, Education Data Mining, Prediction using Fuzzy Logic and Fuzzy Time series 